\title{
The prognostic value of neutrophil to lymphocyte and platelet to lymphocyte ratios for patients with lung cancer
}

\author{
LIQUN WANG ${ }^{1}$, DI LIANG ${ }^{1}$, XIAOLI XU ${ }^{2}$, JING JIN $^{1}$, SHUMEI $^{2}$,

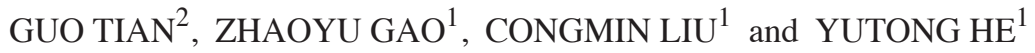 \\ ${ }^{1}$ Division of Analytical Cytology, Cancer Institute of Hebei; ${ }^{2}$ Medical Records Room, The Fourth \\ Hospital of Hebei Medical University, Shijiazhuang, Hebei 050011, P.R. China
}

Received September 18, 2016; Accepted July 14, 2017

DOI: $10.3892 / 01.2017 .7047$

\begin{abstract}
As the leading cause of cancer-associated mortality globally among males in 2012, lung cancer is a disease of particular concern. Previously, the neutrophil-to-lymphocyte ratio (NLR) and the platelet-to-lymphocyte ratio (PLR) were revealed to be prognostic factors for various types of cancer, including lung cancer. In the present study, a retrospective review was conducted with patients who were diagnosed with lung cancer between January 1, 2000 and December 31, 2005 in the Fourth Hospital of Hebei Medical University. A total of 695 patients were included, and the optimal cutoffs of the NLR and the PLR were 6.0 and 248.0, respectively. There were statistically significant associations between tumor-node-metastasis (TNM) stage, surgery, metastasis incidence and NLR $(\mathrm{P}<0.001)$. The associations between TNM stage, surgery incidence and PLR were also revealed to be statistically significant $(\mathrm{P}<0.001)$. Patients in the low NLR group demonstrated longer overall survival (OS) than patients in the high NLR group (819.57 days vs. 629.86 days, $\mathrm{P}=0.041$ ). The NLR at diagnosis was demonstrated to be an independent prognostic factor for OS. Thus, the NLR may be a promising approach for predicting the prognosis of patients with lung cancer.
\end{abstract}

\section{Introduction}

Lung cancer is one of the most common cancers globally. An estimated 1.8 million new lung cancer cases occurred in 2012, accounting for $\sim 13 \%$ of all cancer diagnoses. Lung cancer was the most frequently diagnosed cancer and the leading cause of cancer death for males and females in that same year (1).

Correspondence to: Professor Yutong He, Division of Analytical Cytology, Cancer Institute of Hebei, The Fourth Hospital of Hebei Medical University, 12 Jiankang Road, Shijiazhuang, Hebei 050011, P.R. China

E-mail: hytong69@yahoo.com

Key words: lung cancer, neutrophil-lymphocyte ratio, platelet-lymphocyte ratio, prognosis, survival rate
In less developed countries in Eastern Asia, including China, the incidence and mortality of lung cancer were higher than other cancer types in 2012 (2). The lung cancer burden has significantly increased in Hebei province, China, which is severely polluted, from 1973-1975 to 2010-2011, with a rate of increase of $189.15 \%$ (3). Other studies have proposed that outdoor pollution, which includes increasing concentrations of $\mathrm{SO}_{2}$ emissions, nitrogen oxide emissions or particulate matter 2.5 , as well as an increase in smoking prevalence, has contributed to the increasing rate of lung cancer incidence $(4,5)$. According to a survey by the European Union, lung cancer had the highest economic cost (as high as $€ 18.8$ billion, or $15 \%$ of overall cancer costs) amongst all cancers in 2009 (6).

Although advances have been made in multidisciplinary treatments for lung cancer, this cancer continues to have a poor prognosis due to a general lack of symptoms until it reaches an advanced stage (7). Due to discrepancies between results within the same stage, there is an urgent demand for novel parameters, particularly serum predictive biomarkers, to combine with low-dose computed tomography, x-ray examination and other diagnostic tests to complement tumor-node-metastasis (TNM) staging (8) to accurately predict the prognosis and provide appropriate preoperative patient counseling (9). White blood cell (WBC) counts and WBC subtype counts are well established in systemic inflammatory or infection responses. Wculek and Malanchi hypothesized that an altered presence of leukocytes within distant tissues of tumor-bearing hosts may affect specific subsets of disseminating cancer cells (10). Notably, leukocytes were demonstrated to accumulate in the lung prior to infiltration of the tissue by cancer cells (in a pre-metastatic lung), and their numbers increased during metastatic progression (in a metastatic lung) (10). Increasingly, evidence has demonstrated that a systemic inflammatory response has a prognostic value in various cancers (11-14). Amongst the convenient and available markers, a high ratio of neutrophils to lymphocytes (NLR) and platelets to lymphocytes (PLR), which are calculated from the complete blood count with differential (15), also have been combined to form inflammation-based prognostic scores to predict cancer survival (11). As they are routine laboratory tests, the NLR and PLR are easy to obtain and may serve an important function in predicting the survival and monitoring of cancer progression in patients with lung cancer. Therefore, the present study 
aimed to explore the prognostic values of NLR and PLR in patients with lung cancer.

\section{Materials and methods}

Study population. A retrospective analysis was performed on 695 patients diagnosed with lung cancer from high incidence areas in Hebei Province and treated at the Fourth Hospital of Hebei Medical University (Shijazhuang, China; also known as the Tumor Hospital of Hebei Province, a large and comprehensive hospital with the rank of level three and grade A) from January 1, 2000 to December 31, 2005. All the patients included were histologically confirmed to have lung cancer and received a routine laboratory examination at diagnosis. Patients with pulmonary hypertension and other severe diseases were excluded.

Clinical data collection. Baseline characteristics were collected, including age, sex, occupation, family history, tumor data (pathological type, TNM stage and surgical situation), and laboratory data (hemoglobin levels, neutrophil count, lymphocyte count, and platelet count on the first hospitalized day). The NLR was defined as a simple ratio between the absolute neutrophil count and the absolute lymphocyte count; similarly, PLR was defined as the ratio of the absolute platelet count and the absolute lymphocyte count.

Follow-up studies. The follow-up evaluations were conducted according to the standard follow-up system of the hospital, i.e., every 6 months after patients were discharged from the hospital. The deadline for follow-up evaluations was December 31, 2012. The survival period was measured from the date of admission to the date of mortality or the date of the follow-up deadline.

Statistical analysis. SPSS 21.0 (IBM Corp., Armonk, NY, USA) and Microsoft Office Excel 2007 (Microsoft Corporation, Redmond, WA, USA) were used for statistical analysis. The optimal cutoff values for the NLR and the PLR were determined from the receiver operating curve (ROC) analysis. The comparison between high and low NLR and PLR groups used $\chi^{2}$ tests or the Fisher's exact probability method to explore the associations between the NLR and PLR and other clinicopathological variables. The Kaplan-Meier method for survival analysis was performed. The overall survival (OS) in different groups was identified using the log-rank test. $\mathrm{P}<0.05$ was considered to indicate a statistically significant difference. Univariate and multivariate Cox regression models were performed to analyze the factors that may influence the OS rate.

\section{Results}

A total of 695 patients with lung cancer were included, of which 56 patients were still alive and 639 patients had succumbed, by the end of the follow-up. The follow-up rate was $98.44 \%$. Overall, $510(73.38 \%)$ cases were male, and 185 (26.62\%) were female with an average age of $61.69 \pm 11.07$ years (ranging between 20-89). In total, 232 (33.38\%) patients underwent surgery.

The median absolute neutrophil count was $6.56 \times 10^{6} / \mathrm{ml}$ (ranging between 0.01-87.00), the median absolute platelet count was $276.68 \times 10^{6} / \mathrm{ml}$ (ranging between $6.00-716.00$ ), and the median value of lymphocyte count was $1.89 \times 10^{6} / \mathrm{ml}$ (ranging between 0.11-31.60). Then, ROC curves for OS were used to define the optimal cutoff of NLR and PLR; the results were 6.0 and 248, respectively. The sensitivity and specificity were 69.1 and $43.4 \%$, and 55.7 and $49.9 \%$, respectively.

The associations between the NLR and PLR and the baseline clinical characteristics of lung cancer patients were analyzed (Tables I and II). The clinical variables included age, sex, pathological type, TNM stage, surgery, metastasis, occupation, and family history. 501 patients, accounting for $72.09 \%$ of all patients, were placed into the low NLR group (NLR<6.0), and 194 patients, accounting for $27.91 \%$ of all patients, were placed in the high NLR group. 549 patients, accounting for $78.99 \%$ of all patients, were placed into the low PLR group (PLR<248.0), and 146 patients, accounting for $21.01 \%$ of all patients, were placed into in the high PLR group. The results revealed that there was no association between age, sex, pathological type, occupation, or family history incidence and NLR in different groups, but there was a statistically significant association between the TNM stage, surgery, metastasis incidence and NLR $(\mathrm{P}<0.001)$. No associations between age, sex, pathological type, occupation, family history, or metastasis incidence and PLR was identified, but the association between PLR and both the TNM stage and surgery incidence was statistically significant $(\mathrm{P}<0.001)$.

The association between NLR, PLR and the OS rate of lung cancer patients is presented in Table III. The pathological type, TNM stage, surgery, metastasis, occupational status and NLR were demonstrated to affect the OS rate. The 1-, 3-, and 5 -year OS rates of lung cancer patients in the low NLR group were 54.7, 28.9 and $20.9 \%$, respectively, while those in the high NLR group were 43.6, 24.6 and $17.5 \%$, respectively. Notably, patients in the low NLR group had a significantly longer OS than patients in the high NLR group (819.57 days vs. 629.86 days, $\mathrm{P}=0.041$; Fig. 1). However, there was no significant difference between patients in the low-PLR or high-PLR groups in terms of OS rates during the different follow-up periods $(\mathrm{P}=0.217$; Fig. 2). Furthermore, the potential prognostic factors for OS rates were explored by conducting univariate Cox regression analysis (Table IV).

\section{Discussion}

Lung cancer is one of the leading causes of mortality worldwide in the 21 st century (16), with an equally high incidence between men and women, and between developed countries and less developed countries (17). The dramatic increase in the incidence of lung cancer over the last 40 years (3) established the rationale for developing biomarkers for the prognosis of lung cancer. This stems from the fact that, at the population level, the earlier a disease is predicted, the better the outcome and the lower the health care cost (18). Multiple studies have revealed that environmental and occupational causes, including genetic and sex-specific factors, nutrition, obesity, tobacco smoking, air pollution and, potentially, human papilloma virus infection, are involved in increasing the lung cancer burden $(19,20)$. The International Agency for Research on Cancer (IARC) has classified air pollution 
Table I. Associations between NLR and patient characteristics.

\begin{tabular}{|c|c|c|c|c|}
\hline Factor & Low NLR (n=501) & High NLR (n=194) & $\chi^{2}$ & P-value \\
\hline Age, years & $61.69 \pm 11.07$ & & & \\
\hline Sex & & & 0.744 & 0.388 \\
\hline Male & 373 & 137 & & \\
\hline Female & 127 & 58 & & \\
\hline Age, years & & & 3.312 & 0.069 \\
\hline$<40$ & 26 & 4 & & \\
\hline$\geq 40$ & 475 & 190 & & \\
\hline Pathological type & & & 2.290 & 0.130 \\
\hline Small cell cancer & 46 & 12 & & \\
\hline Non-small cell cancer & 455 & 182 & & \\
\hline TNM stage & & & 20.041 & 0.000 \\
\hline I & 83 & 9 & & \\
\hline II & 158 & 70 & & \\
\hline III & 176 & 68 & & \\
\hline IV & 84 & 47 & & \\
\hline Surgery & & & 41.118 & 0.000 \\
\hline Yes & 203 & 29 & & \\
\hline No & 298 & 165 & & \\
\hline Metastasis & & & 172.154 & 0.000 \\
\hline Yes & 220 & 191 & & \\
\hline No & 281 & 3 & & \\
\hline Occupation & & & 0.061 & 0.804 \\
\hline Labourer & 204 & 77 & & \\
\hline Others & 297 & 117 & & \\
\hline Family history & & & 0.688 & 0.407 \\
\hline Yes & 37 & 18 & & \\
\hline No & 464 & 176 & & \\
\hline
\end{tabular}

NLR, neutrophil-to-lymphocyte ratio; TNM, tumor-node-metastasis.

and particulate matter as carcinogenic to humans $(21,22)$. Although there have been significant advances in the diagnosis and comprehensive treatment of lung cancer, the majority of patients are diagnosed in the late stages of the disease, and the 5-year survival rate and quality of life of these patients remains low (23).

Multiple methods to diagnose and predict the survival of lung cancer have emerged, including pathological confirmation and tumor biomarkers, which include specific RNA, DNA, or the mutation/methylation of nucleic acids of cells and tissues (24-27). Another biomarker, circulating tumor DNA, offers an alternative, temporal and less-invasive option (termed a 'liquid biopsy' due to the biopsy sample being plasma) for accurate early detection with high sensitivity for patients with lung cancer (28). However, the above approaches also have disadvantages. It is always difficult to obtain tumor samples; and, in certain tumors, the tissues are only accessible through fine-needle aspirates, particularly in early stage cases, and the acquisition of samples from different medical centers is challenging or time-consuming particularly as they take a long time to recover. However, NLR and PLR have now been evaluated for use as prognostic factors, and are simple, convenient, damage-free and supplementary to the plethora of biomarkers and other ways with which to predict the survival of patients with tumors.

Inflammation is a physiological process that is a crucial function of the innate immune system, as it is a response to acute or chronic tissue damage, whether resulting from physical injury, ischemic injury, infection, exposure to toxins, or other types of trauma. When these situations occur within the body, the immune system will cause neutrophils, leukocytes, lymphocytes and other inflammatory cells to be activated and then be attracted to the site of damage (29). Currently. there is increasing recognition of the involvement of immune cells and their supporting pro-inflammatory mediators, typically associated with the containment of an inflammatory process, in the pathobiology of multiple types of cancer, including gastrointestinal, liver and breast cancer (30-32). They may be involved in tumor suppression by stimulating an antitumor immune response, but more often, and under certain conditions, this response appears to stimulate tumor development (29). Bollrath et al (33) discovered that the tumor microenvironment 
Table II. Associations between PLR and patient characteristics.

\begin{tabular}{|c|c|c|c|c|}
\hline Factor & Low PLR $(\mathrm{n}=549)$ & High PLR $(n=146)$ & $\chi^{2}$ & P-value \\
\hline Age, years & $61.69 \pm 11.07$ & & & \\
\hline Sex & & & 2.261 & 0.133 \\
\hline Male & 410 & 100 & & \\
\hline Female & 139 & 46 & & \\
\hline Age, years & & & 0.019 & 0.890 \\
\hline$<40$ & 24 & 6 & & \\
\hline$\geq 40$ & 525 & 140 & & \\
\hline Pathological type & & & 1.985 & 0.159 \\
\hline Small cell cancer & 50 & 8 & & \\
\hline Non-small cell cancer & 499 & 138 & & \\
\hline TNM stage & & & 51.371 & 0.000 \\
\hline I & 84 & 7 & & \\
\hline II & 151 & 77 & & \\
\hline III & 219 & 26 & & \\
\hline IV & 95 & 36 & & \\
\hline Surgery & & & 21.969 & 0.000 \\
\hline Yes & 207 & 25 & & \\
\hline No & 342 & 121 & & \\
\hline Metastasis & & & 2.106 & 0.147 \\
\hline Yes & 317 & 94 & & \\
\hline No & 232 & 52 & & \\
\hline Occupation & & & 0.600 & 0.439 \\
\hline Labourer & 223 & 58 & & \\
\hline Others & 326 & 88 & & \\
\hline Family history & & & 1.413 & 0.235 \\
\hline Yes & 40 & 15 & & \\
\hline No & 509 & 131 & & \\
\hline
\end{tabular}

PLR, platelet-to-lymphocyte ration; TNM, tumor-node-metastasis.

is comprised not only of tumor cells but also of stromal cells (including fibroblasts and endothelial cells), cells from the innate immune system (including macrophages, neutrophils, mast cells, myeloid-derived suppressor cells, dendritic cells and natural killer cells) and the adaptive immune cells, $\mathrm{T}$ and B lymphocytes.

Previous studies have begun to unravel the mechanisms linking the host inflammatory response to tumor growth, invasion and metastasis in cancers. Based on this relationship between inflammation and cancer progression, several inflammation-based scores have been demonstrated to have prognostic value in numerous types of malignant solid tumor (34), including lung (35) and liver cancer (36). Accumulating evidence has indicated that long term inflammation-associated factors activate the occurrence and metastasis of certain types of cancer, as systemic inflammatory responses and blood NLR, and local inflammatory responses (including the infiltration of various immune cells and their subsets in tumors) are associated with the prognosis of cancer (37). Certain studies have revealed that the human lung cancer stroma is composed of immune and inflammatory cells $(38,39)$. These studies demonstrated that, in human lung cancer sections, there was a significant elevation/infiltration of total-T lymphocytes $\left(\mathrm{CD}^{+}, 8^{+}, 4^{+}, 20^{+}\right.$etc.) and tumor-infiltrating lymphocytes compared with in healthy donor specimens. All these immune cell markers were observed in different types of lung cancer, and the tumor-infiltrating lymphocytes were more frequent in poorly differentiated tumors and tumors with microscopic vascular invasion.

In the present study, it was discovered that the patients with lung cancer from the low NLR group had a lower OS rate than patients in the high NLR group, which is in accordance with results observed in other types of cancers $(40,41)$. Abbasciano et al (42) hypothesized that the activation and fibrinolysis of platelets may trigger colon cancer. The physiological immune response of circulating leukocytes to various abnormal events is characterized by an increased neutrophil count and decreased lymphocyte count, which results in high NLR and PLR levels (43). When the infection or inflammatory response develops into a chronic disease, the opportunity for tumorigenesis will increase (44). Mediators of chronic inflammation inevitably contribute to tumor initiation, 
Table III. Prognostic factors according to the univariate analysis.

\begin{tabular}{|c|c|c|c|c|c|c|}
\hline \multirow[b]{2}{*}{ Factor } & \multirow[b]{2}{*}{$\mathrm{N}$} & \multicolumn{3}{|c|}{ OS Rate (\%) } & \multirow[b]{2}{*}{$\chi^{2}$} & \multirow[b]{2}{*}{ P-value } \\
\hline & & 1 year & 3 year & 5 year & & \\
\hline $\operatorname{Sex}$ & & & & & 0.234 & 0.628 \\
\hline Male & 510 & 84.6 & 28.7 & 19.7 & & \\
\hline Female & 185 & 78.9 & 25.4 & 21.1 & & \\
\hline Age, years & & & & & 1.735 & 0.188 \\
\hline$<40$ & 30 & 55.7 & 40.0 & 33.3 & & \\
\hline$\geq 40$ & 665 & 51.9 & 27.3 & 19.6 & & \\
\hline Pathological type & & & & & 8.494 & 0.004 \\
\hline Small cell cancer & 58 & 71.1 & 36.3 & 33.6 & & \\
\hline Non-small cell cancer & 637 & 50.0 & 27.1 & 18.9 & & \\
\hline TNM stage & & & & & 69.095 & 0.000 \\
\hline I & 92 & 83.7 & 66.3 & 52.2 & & \\
\hline II & 228 & 50.2 & 24.9 & 19.1 & & \\
\hline III & 245 & 50.8 & 22.2 & 14.0 & & \\
\hline IV & 130 & 36.2 & 16.7 & 9.1 & & \\
\hline Surgery & & & & & 65.848 & 0.000 \\
\hline Yes & 232 & 70.3 & 46.0 & 35.6 & & \\
\hline No & 463 & 43.0 & 18.5 & 12.1 & & \\
\hline Metastasis & & & & & 60.599 & 0.000 \\
\hline Yes & 411 & 43.7 & 17.6 & 10.4 & & \\
\hline No & 284 & 63.4 & 42.4 & 33.8 & & \\
\hline Occupation & & & & & 6.099 & 0.014 \\
\hline Labourer & 281 & 57.7 & 31.3 & 23.5 & & \\
\hline Others & 414 & 48.2 & 25.5 & 17.8 & & \\
\hline Family history & & & & & 0.002 & 0.968 \\
\hline Yes & 55 & 55.2 & 24.7 & 16.6 & & \\
\hline No & 640 & 51.9 & 28.2 & 20.3 & & \\
\hline NLR & & & & & 4.159 & 0.041 \\
\hline Low & 501 & 54.7 & 28.9 & 20.9 & & \\
\hline High & 194 & 43.6 & 24.6 & 17.5 & & \\
\hline PLR & & & & & 1.523 & 0.217 \\
\hline Low & 549 & 52.9 & 28.5 & 21.0 & & \\
\hline High & 146 & 47.4 & 25.6 & 16.7 & & \\
\hline
\end{tabular}

TNM, tumor-node-metastasis; NLR, neutrophil-to-lymphocyte ratio; PLR, platelet-to-lymphocyte ratio.

development and progression. As a consequence, upregulation and overexpression of these molecular mediators often serve as a prognostic marker for patients with cancer (32). Chronic inflammation predisposes and potentially initiates cancer in the host by inducing DNA damage, chromosomal instability, and the production of chemokines, cytokines and growth factors at the inflammatory sites $(45,46)$. When a tumor exists in the body, tumor necrosis factors, including interleukin (IL)-1 and IL-6, will contribute to progression towards malignancy (47). Meanwhile, systemic inflammatory responses towards a tumor may also increase metastasis through the inhibition of apoptosis and augmentation of angiogenesis (48). Neutrophils secrete vascular endothelial growth factor in addition to a pro-angiogenic factor that is involved in tumor development, which is an absolute requirement in tumor growth and metastatic disease (49). Therefore, the high level of NLR may serve a function in predicting the survival of patients with lung cancer.

As there is a high level of specificity of etiology and pathogenicity in high risk areas of lung cancer, the relationship between NLR, PLR and the prognosis of patients with lung cancer was first proposed relating to the Hebei province (9), one of the high risk areas in China, where there was a demonstrable increase in the lung cancer incidence rate from 1973 to 2011. In 2011, the crude lung cancer incidence rate in the registry areas was $45.44 / 100,000$, accounting for $18.44 \%$ of all cancers (3). Comparing the results of the present study with Globocan 2012 
Table IV. Prognostic factors according to multivariate analysis.

\begin{tabular}{lccccr}
\hline Factor & $\beta$ & SE & Wald & RR (95\% CI) & P-value \\
\hline Pathological type & 0.476 & 0.166 & 8.241 & $1.069(1.162-2.227)$ & 0.004 \\
Surgery & -0.730 & 0.093 & 61.273 & $0.482(0.401-0.579)$ & 0.000 \\
Metastasis & 0.673 & 0.089 & 57.536 & $1.960(1.647-2.332)$ & 0.000 \\
TNM Stage I & & & & 1.00 & \\
TNM Stage II & 0.384 & 0.176 & 4.790 & $1.469(1.041-2.072)$ & 0.029 \\
TNM Stage III & 0.269 & 0.102 & 6.800 & $1.310(1.071-1.603)$ & 0.009 \\
TNM Stage IV & 0.509 & 0.104 & 24.212 & $1.661(1.355-2.038)$ & 0.000 \\
NLR & 0.187 & 0.093 & 4.071 & $1.205(1.005-1.445)$ & 0.044 \\
PLR & 0.122 & 0.100 & 1.494 & $1.130(0.929-1.373)$ & 0.222
\end{tabular}

TNM, tumor-node-metastasis; NLR, neutrophil-to-lymphocyte ratio; PLR, platelet-to-lymphocyte ratio; SE, standard error; RR, relative risk; CI, confidence interval.

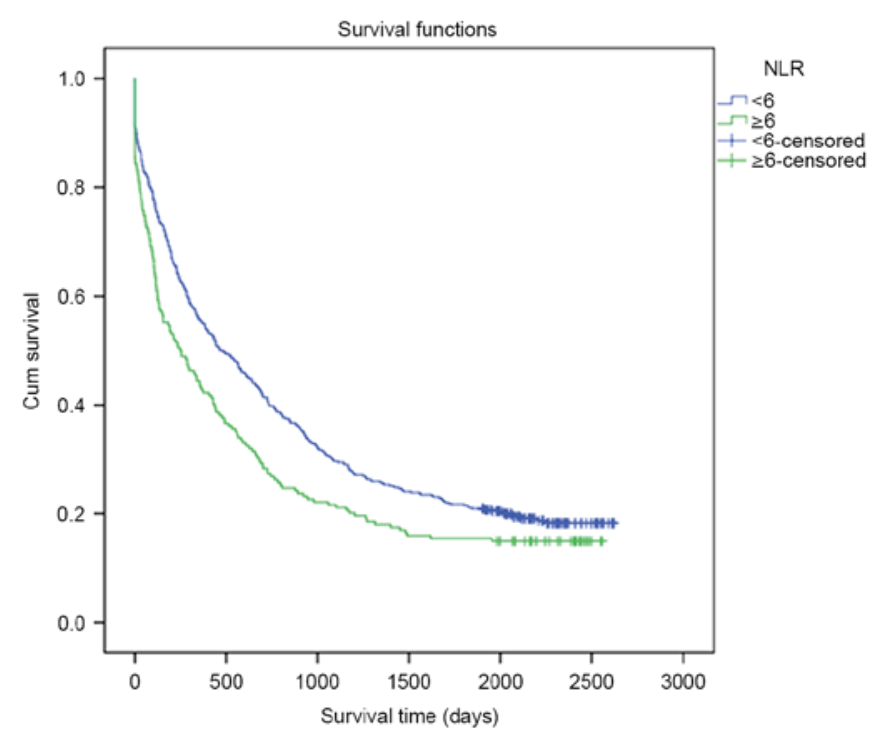

Figure 1. OS rates of patients with lung cancer and differential NLRs. The blue curve represents the low NLR group $(\mathrm{NLR}<6)$, whereas the green curve represents the high NLR group (NLR $\geq 6)$. Patients in the low NLR group indicated longer OS than patients in the high NLR group (819.57 days vs. 629.86 days, $\mathrm{P}=0.041$ ). OS, overall survival; NLR, neutrophil-to-lymphocyte ratio.

data (50), the lung cancer incidence in Hebei Province in 2011 (ASRW=39.01/100,000) was 1.08 times that of China as a whole $(36.1 / 100,000)$ and 1.69 times that of global rates $(23.1 / 100,000)$. The potential association with large-scale samples was explored in the present study, which was consistent with results in esophageal cancer (9). The present study also illustrated that the OS rate of patients with lung cancer with a high NLR level who live in high-risk areas is lower than those with a low NLR level. Hence, the NLR may be a promising approach for predicting the OS rate of lung cancer patients from a high-risk area.

However, although there is a similar mechanism in both PLR and NLR, no potential relationship between PLR and the survival of patients with lung cancer was identified.

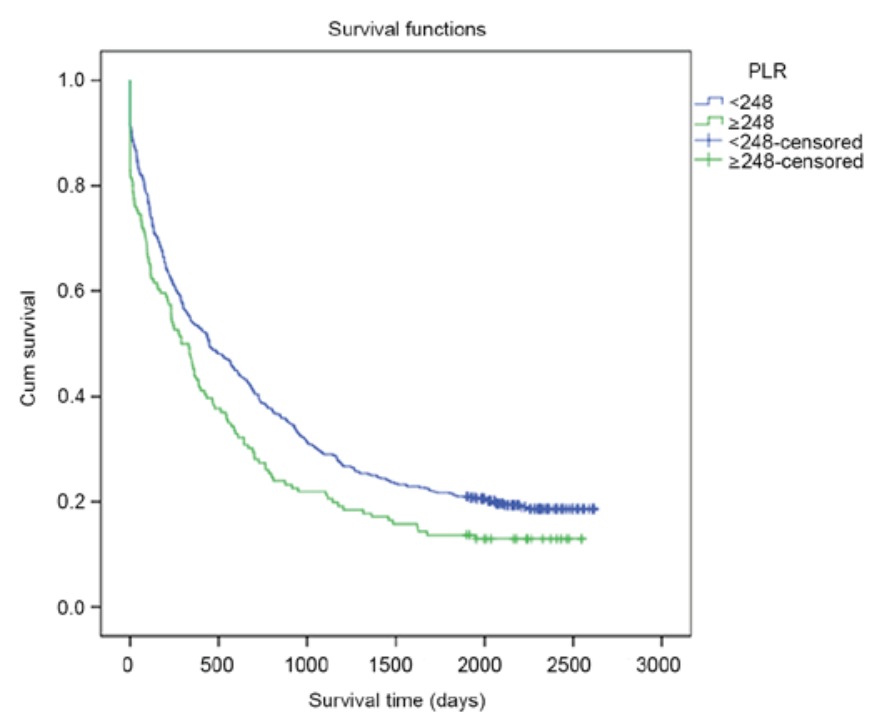

Figure 2. OS rates of patients with lung cancer and differential PLRs. The blue curve represents the low PLR group (PLR $<248$ ), whereas the green curve represents the high NLR group ( $P L R \geq 248$ ). There was no significant difference between OS rates in the low PLR or the high PLR group $(\mathrm{P}=0.217)$. OS, overall survival; PLR, platelet-to-lymphocyte ratio; NLR, neutrophil-to-lymphocyte ratio.

Although there is increasing proof that the NLR and the PLR may be used as prognostic factors in lung cancer, the mechanisms remain unknown. Further studies are required to confirm these results and transition these methods from being largely investigational to potentially being used routinely in lung cancer prognosis.

\section{Acknowledgements}

The present study was supported by grants from the National Natural Scientific Foundation of China (grant no. 81272682) and the Financial Department of the Hebei Province [grant no. (2012)2056]. 


\section{References}

1. Torre LA, Bray F, Siegel RL, Ferlay J, Lortet-Tieulent J and Jemal A: Global cancer statistics, 2012. CA Cancer J Clin 65: 87-108, 2015

2. Chen W, Zheng R, Zuo T, Zeng H, Zhang S and He J: National cancer incidence and mortality in China, 2012. Chin J Cancer Res 28: 1-11, 2016.

3. He Y, Li D, Song G, Li Y, Liang D, Jin J, Wen D and Shan B: Lung cancer burden has increased during the last 40 years in Hebei Province, China. Thorac Cancer 7: 323-332, 2016.

4. Raaschou-Nielsen O, Andersen ZJ, Beelen R, Samoli E, Stafoggia M, Weinmayr G, Hoffmann B, Fischer P, Nieuwenhuijsen MJ, Brunekreef B, et al: Air pollution and lung cancer incidence in 17 European cohorts: Prospective analyse from the European Study of Cohorts for Air Pollution Effects (ESCAPE). Lancet Oncol 14: 813-822, 2013.

5. Hamra GB, Guha N, Cohen A, Laden F, Raaschou-Nielsen O, Samet JM, Vineis P, Forastiere F, Saldiva P, Yorifuji T and Loomis D: Outdoor particulate matter exposure and lung cancer: A systematic review and meta-analysis. Environ Health Perspect 122: 906-911, 2014.

6. Luengo-Fernandez R, Leal J, Gray A and Sullivan R: Economic burden of cancer across the European Union: A population-based cost analysis. Lancet Oncol 14: 1165-1174, 2013.

7. Melloni G, Muriana P, Bandiera A, Fontana R, Maggioni D, Russo V, Doglioni C and Zannini P: Prognostic role of liver X receptor-alpha in resected stage II and III non-small cell lung cancer. Clin Respir J Jul 12, 2016 (Epub ahead of print).

8. Rami-Porta R, Bolejack V, Giroux DJ, Chansky K, Crowley J, Asamura $\mathrm{H}$ and Goldstraw P; International Association for the Study of Lung Cancer Staging and Prognostic Factors Committee, Advisory Board Members and Participating Institutions: The IASLC lung cancer staging project: The new database to inform the eighth edition of the TNM classification of lung cancer. J Thorac Oncol 9: 1618-1624, 2014.

9. Yutong H, Xiaoli X, Shumei L, Shan S, Di L and Baoen S Increased neutrophil-lymphocyte ratio is a poor prognostic factor in patients with esophageal cancer in a high incidence area in China. Arch Med Res 46: 557-563, 2015.

10. Wculek SK and Malanchi I: Neutrophils support lung colonization of metastasis-initiating breast cancer cells. Nature 528 413-417, 2015

11. Chen S, Guo J, Feng C, Ke Z, Chen L and Pan Y: The preoperative platelet-lymphocyte ratio versus neutrophil-lymphocyte ratio: Which is better as a prognostic factor in oral squamous cell carcinoma? Ther Adv Med Oncol 8: 160-167, 2016.

12. Feng Z, Wen H, Bi R, Ju X, Chen X, Yang W and Wu X: Preoperative neutrophil-to-lymphocyte ratio as a predictive and prognostic factor for high-grade serous ovarian cancer. PLoS One 11: e0156101, 2016.

13. Marchioni M, Primiceri G, Ingrosso M, Filograna R, Castellan P, De Francesco P and Schips L: The clinical use of the neutrophil to lymphocyte ratio (NLR) in urothelial cancer: A systematic review. Clin Genitourin Cancer 14: 473-484, 2016.

14. Maeda Y, Kawahara T, Koizumi M, Ito H, Kumano Y, Ohtaka M, Kondo T, Mochizuki T, Hattori Y, Teranishi J, et al: Lack of an association between neutrophil-to-lymphocyte ratio and PSA failure of prostate cancer patients who underwent radical prostatectomy. Biomed Res Int 2016: 6197353, 2016.

15. Lee H, Um SJ, Kim YS, Kim DK, Jang AS, Choi HS, Kim YH, Kim TE, Yoo KH and Jung KS: Association of the neutrophil-to-lymphocyte ratio with lung function and exacerbations in patients with chronic obstructive pulmonary disease. PLoS One 11: e0156511, 2016.

16. Chen JL, Lv XD, Ma H, Chen JR and Huang JA: Detection of cancer embryo antigen and endothelin-1 in exhaled breath condensate: A novel approach to investigate non-small cell lung cancer. Mol Clin Oncol 5: 124-128, 2016.

17. Gandara DR, Grimminger P, Mack PC, Lara PN Jr, Li T, Danenberg PV and Danenberg KD: Association of epidermal growth factor receptor activating mutations with low ERCC1 gene expression in non-small cell lung cancer. J Thorac Oncol 5 : 1933-1938, 2010

18. Atwater T and Massion PP: Biomarkers of risk to develop lung cancer in the new screening era. Ann Transl Med 4: 158, 2016.

19. Field RW and Withers BL: Occupational and environmental causes of lung cancer. Clin Chest Med 33: 681-703, 2012.
20. Dela Cruz CS, Tanoue LT and Matthay RA: Lung cancer: Epidemiology, etiology, and prevention. Clin Chest Med 32: 605-644, 2011.

21. Straif K., Cohen A and Samet J (eds.): Air pollution and cancer. International Agency for Research on Cancer, Lyon, France, pp123-148, 2014.

22. Oberli LS, Valeri F, Korol D, Rohrmann S and Dehler S: 31 years of lung cancer in the canton of Zurich, Switzerland: Incidence trends by sex, histology and laterality. Swiss Med Wkly 146: w14327, 2016.

23. Cedrés S, Nuñez I, Longo M, Martinez P, Checa E, Torrejón D and Felip E: Serum tumor markers CEA, CYFRA21-1, and CA-125 are associated with worse prognosis in advanced non-small-cell lung cancer (NSCLC). Clin Lung Cancer 12: 172-179, 2011.

24. Retraction: HMGA2 functions as a competing endogenous RNA to promote lung cancer progression. Nature 523: 370, 2015.

25. Retraction note to: Identification of featured biomarkers in different types of lung cancer with DNA microarray. Mol Biol Rep 42: 1481, 2015.

26. Agathanggelou A, Honorio S, Macartney DP, Martinez A, Dallol A, Rader J, Fullwood P, Chauhan A, Walker R, Shaw JA, et al: Methylation associated inactivation of RASSF1A from region $3 \mathrm{p} 21.3$ in lung, breast and ovarian tumours. Oncogene 20: 1509-1518, 2001

27. Abdurahman A, Anwar J, Turghun A, Niyaz M, Zhang L and Awut I: Epidermal growth factor receptor gene mutation status and its association with clinical characteristics and tumor markers in non-small-cell lung cancer patients in Northwest China. Mol Clin Oncol 3: 847-850, 2015.

28. Sherwood JL, Corcoran C, Brown H, Sharpe AD, Musilova M and Kohlmann A: Optimised pre-analytical methods improve KRAS mutation detection in circulating tumour DNA (ctDNA) from patients with non-small cell lung cancer (NSCLC). PLoS One 11: e0150197, 2016.

29. Mantovani A and Pierotti MA: Cancer and inflammation: A complex relationship. Cancer Lett 267: 180-181, 2008.

30. Chao $\mathrm{C}$ and Hellmich MR: Gastrin, inflammation, and carcinogenesis. Curr Opin Endocrinol Diabetes Obes 17: 33-39, 2010.

31. Adach A, Ellert-Miklaszewska A and Kaminska B: Molecular characterization of STAT signaling in inflammation and tumorigenesis. Methods Mol Biol 512: 265-278, 2009.

32. Chai EZ, Siveen KS, Shanmugam MK, Arfuso F and Sethi G: Analysis of the intricate relationship between chronic inflammation and cancer. Biochem J 468: 1-15, 2015.

33. Bollrath J and Greten FR: IKK/NF-kappaB and STAT3 pathways: Central signalling hubs in inflammation-mediated tumour promotion and metastasis. EMBO Rep 10: 1314-1319, 2009.

34. Pan QX, Su ZJ, Zhang JH, Wang CR and Ke SY: A comparison of the prognostic value of preoperative inflammation-based scores and TNM stage in patients with gastric cancer. Onco Targets Ther 8: 1375-1385, 2015.

35. Shiels MS, Pfeiffer RM, Hildesheim A, Engels EA, Kemp TJ, Park JH, Katki HA, Koshiol J, Shelton G, Caporaso NE, et al: Circulating inflammation markers and prospective risk for lung cancer. J Natl Cancer Inst 105: 1871-1880, 2013.

36. Sherman M: Hepatocellular carcinoma: Epidemiology, risk factors, and screening. Semin Liver Dis 25: 143-154, 2005.

37. Chang WJ, Du Y, Zhao X, Ma LY and Cao GW Inflammation-related factors predicting prognosis of gastric cancer. World J Gastroenterol 20: 4586-4596, 2014.

38. Banat GA, Tretyn A, Pullamsetti SS, Wilhelm J, Weigert A, Olesch C, Ebel K, Stiewe T, Grimminger F, Seeger W, et al: Immune and inflammatory cell composition of human lung cancer stroma. PLoS One 10: e0139073, 2015.

39. Ruffini E, Asioli S, Filosso PL, Lyberis P, Bruna MC, Macrì L, Daniele L and Oliaro A: Clinical significance of tumor-infiltrating lymphocytes in lung neoplasms. Ann Thorac Surg 87: 365-372, 2009.

40. Absenger G, Szkandera J, Pichler M, Stotz M, Arminger F, Weissmueller M, Schaberl-Moser R, Samonigg H, Stojakovic T and Gerger A: A derived neutrophil to lymphocyte ratio predicts clinical outcome in stage II and III colon cancer patients. Br J Cancer 109: 395-400, 2013

41. Ahn HK, Hwang IC, Lee JS, Sym SJ, Cho EK and Shin DB: Neutrophil-lymphocyte ratio predicts survival in terminal cancer patients. J Palliat Med 19: 437-441, 2016.

42. Abbasciano V, Bianchi MP, Trevisani L, Sartori S, Gilli G and Zavagli G: Platelet activation and fibrinolysis in large bowel cancer. Oncology 52: 381-384, 1995. 
43. Zahorec R: Ratio of neutrophil to lymphocyte counts-rapid and simple parameter of systemic inflammation and stress in critically ill. Bratisl Lek Listy 102: 5-14, 2001 (In English, Slovak).

44. Aggarwal BB, Shishodia S, Sandur SK, Pandey MK and Sethi G: Inflammation and cancer: How hot is the link? Biochem Pharmacol 72: 1605-1621, 2006.

45. Sethi G, Shanmugam MK, Ramachandran L, Kumar AP and Tergaonkar V: Multifaceted link between cancer and inflammation. Biosci Rep 32: 1-15, 2012.

46. Kundu JK and Surh YJ: Inflammation: Gearing the journey to cancer. Mutat Res 659: 15-30, 2008.

47. Balkwill F and Mantovani A: Inflammation and cancer: Back to Virchow? Lancet 357: 539-545, 2001
48. Jackson JR, Seed MP, Kircher CH, Willoughby DA and Winkler JD: The codependence of angiogenesis and chronic inflammation. FASEB J 11: 457-465, 1997.

49. Kusumanto YH, Dam WA, Hospers GA, Meijer C and Mulder NH: Platelets and granulocytes, in particular the neutrophils, form important compartments for circulating vascular endothelial growth factor. Angiogenesis 6: 283-287, 2003.

50. Torre LA, Bray F, Siegel RL, Ferlay J, Lortet-Tieulent J and Jemal A: Global cancer statistics, 2012. CA Cancer J Clin 65: 87-108, 2015 